\title{
Pengelolaan Stres Kerja dan Pengaruhnya terhadap Kinerja Perawat Rumah Sakit Ibnu Sina Makassar di Masa Pandemi Covid 19
}

\author{
Ramlawati $^{\otimes 1}$, Ilham Safar ${ }^{2}$ \\ 1Manajemen, Universitas Muslim Indonesia \\ 2Manajemen, Universitas Fajar \\ DOI : https://doi.org/10.37531/ecotal.v3i1.114
}

\begin{abstract}
ABSTRAK
Penelitian ini menggunakan pendekatan kuantitatif. Teknik pengumpulan data pada skripsi ini yaitu penyebaran kuesioner secara online (Google form) dan offline kepada 51 responden. Hasil penelitian menunjukkan bahwa: 1) Strategi pengelolaan stress kerja yang berfokus pada penyelesaian masalah mempunyai pengaruh positif dan signifikan terhadap kinerja perawat rumah sakit ibnu sina makassar. 2) Strategi Pengelolaan stress kerja yang berfokus pada perbaikan mental dan emosi mempunyai pengaruh positif dan signifikan terhadap kinerja perawat rumah sakit ibnu sina makassar. 3) Pengaruh strategi pengelolaan stress kerja perawat rumah sakit ibnu sina makassar terhadap kinerja di era pandemi covid-19 berpengaruh positif terhadap kinerja perawat.
\end{abstract}

Kata Kunci:

Strategi, Stres, Kinerja

Abstract : The data collection technique in this thesis is distributng quetionnaires online (Google form) and offline to 51 respondents. The results showed that : 1) Work Stress management strategies that focus on problem solving have a positive and significant impact on the performance of nurses at the ibnu sina hospital makassar. 2) Work stress management strategies that focus on mental and emotional improvement have a positive and significant impact on the performance of nurses at the ibnu sina hospital in makassar. 3) The influence of work stress management strategies for nurses at the ibnu sina Makassar Hospital on performance of nurses.

Keywords : Strategy, Stress, Performance

$\triangle$ Corresponding Author :

E-mail address: ramlawati@gmail.com

“Received 08 February 2021, Accepted 14 Juny 2021, Published 27 January 2022" 


\section{Pendahuluan}

Saat ini covid-19 merupakan isu global yang berpengaruh pada seluruh tenaga kerja kesehatan rumah sakit baik di negara maju maupun negara berkembang. Hal ini dikarenakan oleh dampak covid-19 yang sedang melanda dunia, covid-19 menyebabkan perubahan psikologis seperti ketakutan, kecemasan, ketidakamanan dan depresi. Wabah covid-19 mulai masuk ke Indonesia sejak maret 2020, sampai hari ini tingkat penyebaran masih sangat tinggi. Hal ini tentu menjadi sebuah tantangan bagi seluruh masyarakat, bukan hanya pemerintah tetapi seluruh masyarakat juga harus mengambil peran dalam menangani covid-19.

Penelitian terbaru melaporkan bahwa orang yang telah diisolasi dan dikarantina memiliki perubahan signifikan pada tingkat kecemasan, kebingunan, dan stress. Sedangkan masyarakat yang diluar tempat karantina mengalami ketakutan akan tertular karena kurangnya pemahaman tentang covid-19. Hal inilah yang kemudian semakin menghantui perawat, karena disamping menangani pasien yang diisolasi dan dikarantina, perawat juga menjadi masyarakat biasa selepas kerja yang memungkinkan mereka untuk berkumpul dengan keluarga. Perawat rumah sakit sebagai garda terdepan dalam penanganan pasien covid-19 semakin tertekan karna meningkatnya beban pekerjaan, khawatir dengan kesehatan dan keluarganya (Cheng et a.,2020). Perawat merupakan suatu pekerjaan yang mempunyai pengaruh yang sangat penting untuk menentukan berhasilnya rumah sakit dalam memberikan perawatan kesehatan terhadap masyrakat, hal demikian dalamwaktu 24 jam perawat melakukan perawatn serta menghadapi masalah kesehatan pasien secara terus - menerus. Perawat diharuskan selalu siap serta siaga dalam melaksanakan tugas pelayanan dan juga harus selalu memantau perkembangan kondisi pasien selama jam operasional, hal demikian yang membuat perawat biasa mengalami stress.

Penerapan social distancing di era pandemi seperti saat ini pekerja dituntut melakukan aktivitas berdasarkan WFH, seluruh tempat kerja maupun usaha-usaha bisnis ditutup. Pekerja yang terbiasa melakukan aktivitas diluar rumah masalah yang dihadapi tdak begitu berat. Namun, pekerja bida bidang jasa maupun produksi yang seharusnya mereka bekerja dari rumah akan menyebabkan masalah yang besar. Tidak ada yang tahu kapan masa pandemi ini akan berakhir. Dan perusahan yang melakukan PHK begitu banyak lantaran sedikitnya aktivitas bagi pekerja. Kemudian yang melalukan bisnis produktivitas mengalami penurunan.inilah salah satu stress kerja di masa pandami ini.

Stress merupakan masalah psikologi yang dialamai oleh seseorang di tempat kerja, stress diakibatkan oleh tekanan dan beban kerja yang yang melebihi kemampuannya, orang yang 
Ramlawati $^{\bowtie 1}$, Ilham Safar ${ }^{2}$

Pengelolaan Stres Kerja dan Pengaruhnya terhadap Kinerja.....

DOI : https://doi.org/10.37531/ecotal.v3i1.114

terkena stress cenderung tidak produktif dalam melakukan pekerjaan, stress kerja banyak dialami oleh para pekerja di bagian kesehatan utamanya perawat rumah sakit. Seluruh pegawai yang berada di rumah sakit mempunyai resiko stress, tapi perawat memiliki tingkat stress yang sangat tinggi. Hal ini disampaikan pada pasal 63 Ayat a1 Undang-Undang Nomor 36 Tahun 2009 mengenai kesehatan yang berbunyi bahwa penyakit dapat disembuhkan dengan pengendalian, pengobatan, dan perawatan. Dari hal tersebut, perawat dinyatakan bahwa ia bertanggung jawab terhadap kesehatan pasien sehingga apabila perawat mengalami stress, hal tersebut dapat berdampak pada kinerja perawat itu sendiri yang dapat mengakibatkan kurang maksimalnya penanganan pasien. Maka dari itu perlunya implikasi manajemen rumah sakit, bahwa beban kerja dan sarana/prasarana perlu mendapatkan perhatian khusus, sebaiknya diantisipasi dengan cepat dan tepat agar tidak memperparah stress kerja perawat. Terdapat beberapa factor yang dapat menimbulkan stress kerja ialah konflik pribadi dengan pimpinin, beban kerja yang sangat berlebihan, kurangnya waktu yang diberikan dalam menyelesaikan pekerjaan, sikap pemimpin yang kurang adil serta memberrikan tekanan yang tidak wajar.

Mengingat perawat merupakan garda terdepan dalam pelayanan kesehatan di rumah sakit dan sangat rentang mengalami stress maka perlunya perencanaan strategi yang memungkinkan bagi rumah sakit untuk mengantisipasi kondisi perawat yang mengalami stress. Perencanaan strategi merupakan perangkat manajemen penting yang dapat membantu rumah sakit dalam melakukan tugasnya dengan lebih baik. Perencanaan strategi sangat penting bagi organisasi dalam mempertahankan kelangsungannya, (Wheelen dan Hunger,2004).

\section{Kajian Literatur}

\subsection{Stress Kerja}

Wijono (2010) menerangakan stress kerja ialah kondisi penghayalan dari seseorang yang berupa interaksi antara individu dengan kerjaanya yang bisa memeberikan tekanan kepada seseorang. Perawat secara konsisten dilaporkan sebagai pekerja dengan tingkat stress kerja paling tinggi dari semua tenaga kerja yang ada dibidang kesehatan, stress kerja perawat mengacu pada kondisi banyaknya tekanan dan beban pekerjaan (Robert, 2012).

\subsection{Kinerja}

Kinerja merupakan pencapaian seseorang dalam melakukan tugas pada pekerjaan di dalam suatu organisasi sesuai dengan apa yang telah diberikan kepadanya dan apa yang telah diselesaikan atau tentang bagaimana individu bertindak sesuai dengan beban pekerjaan yang 
telah di berikan kepadanya serta kuantitas, kualitas, dan waktuyang dipergunakan di dalam melaksanakan tugas (Sutrisno, 2017). Kinerja merupakan hasil kerja dari individu yang dapat diukur pada waktu periode tertentu yang di dasarkan kesepekatan dan ketentuan telah disetujui.

\subsection{Perawat}

Perawat merupakan orang yang telah menyelesaikan pendidikan keperawatan, sesuai dengan ketentuan perundangan yang berlaku (Republik Indonesia Keputusan Menteri Kesehatan Republik Indonesia, 2002). Wardah (2017) mengemukakan perawat merupakan tenaga kerja yang memiliki kemampuan secara professional, berhak dan bertanggung jawab dalam melaksanakan tugasnya.

\section{Metode Penelitian}

Penelitian ini merupakan penelitian yang berjenis kuantitatif deskriptif yang akan melihat pengaruh variabel bebas terhadap variabel terikat. Variabel bebas dalam penelitian ini yaitu strategi pengelolaan stress kerja yang berfokus pada penyelesaian masalah sebagai (X1) dan strategi pengelolaan stress kerja yang berfokus pada perbaikan mental dan emosi sebagai (X2), sementara yang menjadi variabel terikat yaitu kinerja perawat. Penelitian ini dilakukan pada Rumah Sakit Ibnu Sina Makassar dengan responden sebanyak 51 responden.

Tempat penelitian dilakukan di Rumah Sakit Ibnu Sina Kota Makassar Yng ber alamat di Jl. Poros Makassar - Maros, Panaikang, Kec. Panakkukang, Kota Makassar, Sulawesi Selatan 90231. Penelitian ini dilakukan selama kurang lebih 1 bulan terhitung mulai pada bulan mei hingga juni 2021.Teknik yang digunakan dalam pengumpulan data penelitian ini menggunakan teknik penyebaran kuesioner offline dan online yang berisi pertanyaan.

\section{Hasil Penelitian dan Pembahasan}

\subsection{Karekteristik Responden berdasarkan jenis kelamin}

Data yang digunakan dalam penelitian ini adalah data primer yang diperoleh dengan menyebarkan kuesioner secara offline dan online melalui google form kepada responden. Responden penelitian ini adalah perawat rumah sakit Ibnu Sina Makassar. Sampel yang diambil berjumlah 51 responden, 31 responden secara offline dan 20 responden secara online melalui google form, berdasarkan penelitian yang dilakukan, maka diperoleh data sebagai berikut : 
Tabel 1. Karakteristik Responden Berdasarkan Jenis Kelamin

\begin{tabular}{|c|c|c|c|}
\hline No. & Jenis Kelamin & Jumlah & Persentase \\
\hline 1 & Laki-Laki & 18 & $35 \%$ \\
\hline 2 & Perempuan & 33 & $65 \%$ \\
\hline $\mathbf{3}$ & Total & $\mathbf{5 1}$ & $\mathbf{1 0 0 \%}$ \\
\hline
\end{tabular}

Sumber: Ouput SPSS, 2021

Dapat dilihat pada tabel 1 bahwa jumlah responden adalah 18 untuk laki-laki dengan jumlah persentase 35\% dan 33 responden untuk perempuan dengan persentase 65\%, sehingga dapat disimpulkan bahwa sebagian besar responden adalah perempuan.

\section{Uji Persial (t)}

Uji t untuk menguji pengaruh masing-masing variabel bebas terhadap pariabel terikat dengan menggunakan tingkat signifikansi sebesar 5\%. Jika nilai signifikansi > 0,05 maka HO diterima dan Ha ditolak, artinya variabel independen tidak berpengaruh terhadap variabel dependen. Sebaliknya jika nilai signifikansi $<0,05$ maka Ho ditolak dan Ha diterima, artinya variabel independen berpengaruh terhadap variabel dependen. Hasil uji t dapat dilihat sebagai berikut:

Tabel 2. Hasil Uji Persial (t) Fokus Penyelesaian Masalah

\begin{tabular}{|c|c|c|c|c|c|c|}
\hline \multicolumn{7}{|c|}{ Coefficients $^{2}$} \\
\hline \multicolumn{2}{|c|}{ Model } & \multicolumn{2}{|c|}{ Unstandardized Coefficients } & \multirow{2}{*}{$\begin{array}{c}\text { Standardized } \\
\text { Coefficients }\end{array}$} & \multirow[t]{2}{*}{$\mathrm{T}$} & \multirow[t]{2}{*}{ Sig. } \\
\hline & & B & $\begin{array}{l}\text { Std. } \\
\text { Error }\end{array}$ & & & \\
\hline \multirow[t]{2}{*}{1} & (Constant) & 15.112 & 3.489 & & $\begin{array}{r}4.3 \\
32\end{array}$ & .000 \\
\hline & $\begin{array}{l}\text { Folus } \\
\text { Penyelesai } \\
\text { Masalah }\end{array}$ & .586 & .081 & .717 & $\begin{array}{r}7.2 \\
03\end{array}$ & .000 \\
\hline
\end{tabular}

Sumber: Ouput SPSS, 2021

Hasil uji t menunjukan bahwa t hitung strategi pengelolaan stress kerja yang berfokus pada penyelesaian masalah sebesar 4,332 lebih besar dari t tabel 1.299 dengan nilai signifikansinya 0.000 hal ini menunjukkan bahwa strategi pengelolaan stress kerja yang berfokus pada 
penyelesaian masalah mempunyai pengaruh positif dan signifikan terhadap kinerja perawat rumah sakit ibnu sina makassar.

Tabel 3. Hasil Uji Persial (t) Fokus Perbaikan Mental dan Emosi

\begin{tabular}{|c|c|c|c|c|c|c|}
\hline \multicolumn{7}{|c|}{ Coefficients $^{a}$} \\
\hline \multirow{2}{*}{\multicolumn{2}{|c|}{ Model }} & \multicolumn{2}{|c|}{$\begin{array}{l}\text { Unstandardized } \\
\text { Coefficients }\end{array}$} & \multirow{2}{*}{ 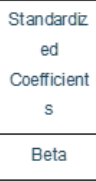 } & \multirow[t]{2}{*}{$\mathrm{T}$} & \multirow[t]{2}{*}{ Sig. } \\
\hline & & B & Std. Error & & & \\
\hline \multirow[t]{2}{*}{1} & (Constant) & 25.272 & 2.145 & & 11.78 & .000 \\
\hline & $\begin{array}{l}\text { Fokus Perbaikan } \\
\text { Mental dan Emosi }\end{array}$ & .385 & .055 & .709 & 7.030 & .000 \\
\hline \\
\hline
\end{tabular}

Sumber: Ouput SPSS, 2021

Hasil uji t menunjukkan bahwa thitung strategi pengelolaan stress kerja yang berfokus pada perbaikan mental dan emosi sebesar 11,784 lebih besar dari t tabel 1.299 dengan nilai signifikansinya 0.000 hal ini menunjukkan bahwa strategi pengelolaan stress kerja yang berfokus pada perbaikan mental dan emosi mempunyai pengaruh positif dan signifikan terhadap kinerja perawat rumah sakit ibnu sina makassar.

3. Uji F

Uji hipotesis simultan bertujuan mengukur pengaruh variabel independen terhadap variabel dependen. Tabel uji hipotesis untuk uji F adah sebagai berikut:

Tabel 4. Hasi Uji F

\begin{tabular}{|l|l|r|r|r|r|c|}
\hline \multicolumn{7}{|l|}{ ANOVA $^{2}$} \\
\hline \multirow{2}{|l|}{ Model } & $\begin{array}{c}\text { Sum of } \\
\text { Squares }\end{array}$ & \multicolumn{1}{c|}{ df } & $\begin{array}{c}\text { Mean } \\
\text { Square }\end{array}$ & F & Sig. \\
\hline 1 & Regression & 489.594 & 2 & 244.797 & 36.256 & $.000^{b}$ \\
\cline { 2 - 7 } & Residual & 324.092 & 48 & 6.752 & & \\
\cline { 2 - 7 } & Total & 813.686 & 50 & & & \\
\hline \multicolumn{7}{|l|}{ a. Dependent Variable: Kinerja } \\
\hline \multicolumn{7}{|l|}{ b. Predidors: (Constant), Fokus Perbaikan Mental dan Emosi, Fokus Penyelesai Masalah } \\
\hline
\end{tabular}

Sumber: Ouput SPSS, 2021

Pada tabel diatas uji F di ketahui nilai signifikansi untuk pengaruh X1 dan X2 secara simultan terhadap Y adalah sebesar 0,000 lebih kecil dari 0,05 dan nilai F hitungan 36,356 lebih besar dari F tabel nilai 4,038 sehingga dapat disimpulkan bahwa hipotesis yang diterima yaitu X1 dan X2 mempengaruhi variabel Y secara simultan. 


\section{Uji Koefiesin Determina si $\left(\mathrm{R}^{2}\right)$}

Uji determinasi dilakukan untuk mengetahui seberapa besar pengaruh variabel $\mathrm{X}$ terhadap variabel Y. Dapat dilihat pada tabel berikut ini:

Tabel 5. Hasil Uji Koefiesin Determinasi

\begin{tabular}{|l|r|r|r|c|}
\hline \multicolumn{5}{|c|}{ Model Summary } \\
\hline Model & R & R Square & Adjusted R Square & $\begin{array}{c}\text { Std. Error of the } \\
\text { Estimate }\end{array}$ \\
\hline 1 & $.776^{\circ}$ & .602 & .585 & 2.598 \\
\hline \multicolumn{3}{|l|}{ a. Predictors: (Constant), Fokus Perbaikan Mental dan Emosi, Fokus Penyelesai Masalah } \\
\hline
\end{tabular}

Sumber: Ouput SPSS, 2021

Berdasarkan tabel 4.14, nilai R2 menunjukkan nilai 0.602 Ini berarti pengaruh variabel X terhadap variabel Y sebesar $60,2 \%$. Maka sisanya $(100 \%-60,2 \%=39,98 \%)$ dipengaruhi oleh variabel-variabel yang tidak diteliti dalam penelitian ini.

5. Uji Regresi Linear Berganda

Metode analisis linear berganda digunakan bertujuan agar peneliti mampu mengetahui arah dan besarnya kaitan antara variabel bebas yaitu kinerja perawat terhadap variabel terikat yaitu strategi pengelolaan stresss kerja. Dari hasil olah data, maka diperoleh persamaan regresi berganda yaitu

Tabel 6. Hasil Uji Regresi Linear Berganda

\begin{tabular}{|c|c|c|c|c|c|c|}
\hline \multicolumn{7}{|c|}{ Coefficients $^{a}$} \\
\hline \multirow{2}{*}{\multicolumn{2}{|c|}{ Model }} & \multicolumn{2}{|c|}{$\begin{array}{l}\text { Unstandardized } \\
\text { Coe fficients }\end{array}$} & \multirow{2}{*}{$\begin{array}{c}\begin{array}{c}\text { Standardize } \\
\text { d } \\
\text { Coefficients }\end{array} \\
\text { Beta }\end{array}$} & \multirow[t]{2}{*}{$\mathrm{T}$} & \multirow[t]{2}{*}{ Sig. } \\
\hline & & B & Std. E rror & & & \\
\hline \multirow[t]{3}{*}{1} & (Constant) & 16.380 & 3.216 & & 5.094 & .000 \\
\hline & $\begin{array}{l}\text { Fokus Penyelesai } \\
\text { Masalah }\end{array}$ & .356 & .103 & .436 & 3.464 & .001 \\
\hline & $\begin{array}{l}\text { Fokus Perbaikan } \\
\text { Mental dan Emosi }\end{array}$ & .222 & .068 & .408 & 3.246 & .002 \\
\hline
\end{tabular}

Sumber: Ouput SPSS, 2021

Berdasarkan analisi regresi berganda pada tabel diatas maka diperoleh nilai konstanta sebesar 16,380 nilai koefisien regresi variabel fokus penyelesaian masalah 0,356 dan nilai koefisien variabel fokus perbaikan mental dan emosi sebesar 0,222. Maka persamaan regresi berganda yaitu : 
$Y=16,380+0,356 X_{1}+0,222 X_{2}+100 \%$

Persamaan regresi berganda ini dapat diinterpretasikan seperti :

1. Konsta dengan nilai 16,380 artinya apabila aspek penyelesaian masalah serta fokus perbaikan masalah mengalami konstan, maka kinerja karyawan pada rumah sakit ibnu sina Makassar sebesar 16, 380\%.

2. Koefisien regresi penyelesaian masalah sebesar 0,356 artinya apabila penyelesaian masalah meningkat satu satuan, maka kinerja karyawan akan meningkan sebesar 0,356. Begitu pun sebaliknya, apabila penyelesaian masalah menurun secara bertahap, menandakan kinerja perawat dapat menurun sebesar 0,356.

3. Koefisien regresi fokus perbaikan mental sebesar 0,222 artinya jika fokus perbaikan mental meningkat satu satuan, maka fokus perbaikan mental akan meningkat sebesar 0,222. Begitupun sebaliknya, apabila fokjus perbaikan mental menurun maka kinerja perawat ikut menurun sebesar 0,222 .

\section{Pembahasan}

Berdasarkan hasil penelitian pada pengelolaan stresss kerja perawat rumah sakit ibnu sina Makassar melalu hasil spss dan hasil survey lapangan dengan menggunakan kuesioner. Kuesioner dibagikan secara online dan secara offline mengingat keadaan yang belum memungkinkan untuk dapat melakukan penyebaran kuesioner secara tatap muka. Adapun jumlah sampel yang digunakan peneliti sebanayak 51 responden. Maka hasil yang diperoleh peneliti sebagai berikut:

\section{Pengaruh Strategi Pengelolaan Stress Kerja Yang Berfokus Pada Penyelesaian Masalah Terhadap kinerja Perawat

Dari hasil uji t menunjukan bahwa thitung strategi pengelolaan stress kerja yang berfokus pada penyelesaian masalah sebesar 4,332 lebih besar dari t tabel 1.299 dengan nilai signifikansinya 0.000 hal ini menunjukkan bahwa strategi pengelolaan stress kerja yang berfokus pada penyelesaian masalah mempunyai pengaruh positif dan signifikan terhadap kinerja perawat rumah sakit ibnu sina makassar. Hal demikian ditunjukkan pada pertanyaan yang memiliki pengaruh tertinggi pada variabel starategi pengelolaan stress kerja yang berfokus pada penyelesaian masalah bahwa pekerjaan selama masa pandemi memiliki resiko yang besar bagi kelurga tetapi untuk melakukan harus tetap professional dan semnagat kerja, maka dapat 
Ramlawati $^{\bowtie 1}$, Ilham Safar ${ }^{2}$

Pengelolaan Stres Kerja dan Pengaruhnya terhadap Kinerja.....

DOI : https://doi.org/10.37531/ecotal.v3i1.114

disimpulkan bahwa penerapan sikap professional yang membuat perawat rumah sakit ibnu sina makassar semanagat dalam melakukan pekerjaan.

\section{Pengaruh Pengelolaan Stresss Kerja Yang Berfokus Pada Perbaikan Mental dan Emosi Terhadap Kinerja Perawat}

Dari hasil uji t menunjukkan bahwa t hitung strategi pengelolaan stress kerja yang berfokus pada perbaikan mental dan emosi sebesar 11,784 lebih besar dari t tabel 1.299 dengan nilai signifikansinya 0.000 hal ini menunjukkan bahwa strategi pengelolaan stress kerja yang berfokus pada perbaikan mental dan emosi mempunyai pengaruh positif dan signifikan terhadap kinerja perawat rumah sakit ibnu sina makassar. Hal demikian ditunjukkan pada pertanyaan yang memiliki pengaruh tertinggi pada variabel starategi pengelolaan stress kerja yang berfokus pada perbaikan mental dan emosi bahwa pekerjaan sebagai perawat merupakan pekerjaan yang bernilai ibadah, maka dapat disimpulkan bahwa penerapan sikap kepercayaan diri terhadap pekerjaan yang membuat mereka merasa melakukan pekerjaan yang bernilai ibadah.

\section{Pengaruh Strategi Pengelolaan Stress Kerja Terhadap Kinerja Perawat}

Dari hasil uji F uji F di ketahui nilai signifikansi untuk pengaruh X1 dan X2 secara simultan terhadap Y adalah sebesar 0,000 lebih kecil dari 0,05 dan nilai F hitungan 36,356 lebih besar dari F tabel nilai 4,038 sehingga dapat disimpulkan bahwa hipotesis yang diterima yaitu X1 dan X2 mempengaruhi variabel Y secara simultan.

Untuk uji koefiesin determinasi nilai R2 menunjukkan nilai 0.602 Ini berarti pengaruh variabel X1 dan X2 terhadap variabel Y sebesar 60,2\% dan sisahnya sebesar 39,98\% dipengaruhi oleh variabel-variabel yang tidak diteliti dalam penelitian ini. Oleh karena itu dua variabel diatas yaitu strategi pengelolaan stresss kerja yang berfokus pada penyelesaian masalah dan strategi pengelolaan stresss kerja yang berfokus pada perbaikan mental dan emosi melalui berbagai pengujian diatas dapat disimpulkan bahwa pengaruh strategi pengelolaan stresss kerja perawat rumah sakit ibnu sina makassar terhadap kinerja di era pandemi covid-19 berpengaruh positif terhadap kinerja perawat. Hal demikian ditunjukkan pada pertanyaan yang memiliki pengaruh tertinggi pada variabel kinerja bahwa pimpinan saya membuat saya nyaman dalam bekerja, maka dapat disimpulkan bahwa pimpinan rumah sakit ibnu sina makassar mampuh membuat perawat merasa nyaman. 


\section{Kesimpulan}

Berdasarkan hasil penelitian uji statistik dapat diketahui bahwa beberapa stretegi pengelolaan stresss kerja berpengaruh positif dan signifikan terhadap kinerja perawat. Strategi pengelolaan stresss kerja berdampak positif , memiliki arti semakin positif strategi pengelolaan stresss kerja maka semakin tinggi kinerja perawat pada rumah sakit ibnu sina makassar. Hasil ini sesuai hipotesis yang diajukan. Strategi pengelolaan stresss kerja yang berfokus pada penyelesaian masalah yang menunjukkan angka yang tinggi bahwa pekerjaan selama masa pandemi memiliki risiko yang besar bagi keluarga tetapi untuk melakukan harus tetap professional dan semangat kerja dan didukung oleh starategi penegelolaan stresss kerja yang berfokus pada perbaikan mental dan emosi menunjukkan angkka tertinggi yaitu pimpinan yang membuat meraka merasa nyaman dalam bekerja selain itu perawat rumah sakit ibnu sina makassar merasa bahwa pekerjaan yang mereka jalani bernilai ibadah.

\section{References :}

Cheng, Q., Liang, M., Li, Y., He, L., Guo, J., Fei, D., Zhang, Z. (2020). Correspondence Mental health care for medical staff in China during the COVID-19. Lancet, 7, 15-26. https:// doi.org/10.1016/S2215-0366(20)30078-X.

Robert, R, Grubb, P. L., dan Grosch, J. W. 2012 Allevating Jpb Stresss In Nurses. http:/www.medscape.cpm/viewarticle/765974_1.

Safar, Ilham. Nurdin. 2019, Stres Kerja Buruh Perempuan Di Kota Makassar. Jurnal Sinar Manajemen Vol. 6 No. 1, hal 20-26.

Sutrisno, E. 2017. Manajemen Sumber Daya Manusia. Kencana, Jakarta.

Wardah, Febrina, Dewi. (2017). Pengaruh Pengetahuan Perawat Dalam Pemenuhan Perawatan Spiritual Pasien Di Ruang Intensif. Jurnal Edurance, Vol 2 No 3.

Wheelen \& Hunger. (2004). Strategic Management And Business Policy, Pearson.

Wijono, Sutarto. (2010). Psikologi Industri dan Organisasi. Jakarta: Fajar Interpratama Offset. Yogyakarta : Gava Media. 